\title{
Impact of IL28B Polymorphism on the Response to Treatment of Hepatitis C with Interferon Based Therapy or Direct Acting Antivirals
}

\author{
AYMAN YOUSRY, M.D.*; MOHAMAD S. ABDEL AZIZ, M.D.*; OLFAT G. SHAKER, M.D.**; \\ DALIA A. OMRAN, M.D.* and MOHAMED S. EL NEKLAWI, M.Sc.*** \\ The Department of Endemic Medicine* \& Biochemistry**, Faculty of Medicine, Cairo University and \\ Department of Endemic Medicine***, National Hepatology \& Tropical Medicine Research Institute (NHTMRI), Cairo, Egypt
}

\begin{abstract}
Background: A major impact of the IL28B gene polymorphism on the response to antiviral therapy in chronic hepatitis $\mathrm{C}$ have been described recently by a lot of studies. This study aims to scrutinize the impact of IL28B genotypes of donors and recipients on the response to treatment with INF based therapy or DAA among patients that underwent liver transplantation.
\end{abstract}

Aim of Study: This study aims to correlate IL28B genotype of donors and recipients for patients that had undergone liver transplantation with the response to INF based therapy, and the response to Direct Acting Antivirals (DAA).

Patients and Methods: Donor and recipient IL28B genotyping by PCR was done for 24 patients who experienced LT for HCV-induced end stage liver disease with established standard follow up evaluations post liver transplant for two years. Pegylated interferon- a (PEG-IFN-a) and ribavirin were received by 10 of the patients and direct acting antiviral (DAA) agents were offered to the remaining 14 patients.

Results: We found that there was no impact of IL 28B polymorphism on the response to anti viral treatment (AVT) by (DAA) agents, as all different IL 28B genotypes and different recipient/donor patterns eventually achieved SVR even in cases with two unfavorable non-CC genotypes in both recipients and donors. We also found that the donor rs 12979860 CC genotype was strongly associated with the success of PEG-IFN-a and ribavirin treatment of recurrent hepatitis C.

Conclusions: In the era of DAAs, it seems likely that it will be possible to overcome the effect of IL28B polymorphism with DAAs combinations.

Key Words: Antiviral therapy - Chronic hepatitis $C-D A A$ - Single nucleotide polymorphisms - INF based therapy.

\section{Introduction}

LIVER transplantation (LT) is an established, effective and lifesaving treatment for acute and

Correspondence to: Dr. Ayman Yousry, The Department of Endemic Medicine, Faculty of Medicine, Cairo University, Cairo, Egypt chronic end stage liver disease (ESLD). LT has evolved rapidly, becoming the standard therapy for acute and chronic liver failure of all etiologies, with more than 80,000 procedures performed to date. Survival rates have improved significantly in the last 25 years, achieving rates of $96 \%$ and $71 \%$ at 1 and 10 years after LT respectively [1] .

Over the last decades major advances in diagnosis, preoperative patient assessment, donor organ preservation, immunosuppressive therapy, surgical, anesthetic and intensive care techniques, and improved assessment and management of postoperative complications have resulted in increased patient and graft survival. This great success is mostly attributable to several advances such as the introduction of new immunosuppressive agents and preservation solutions, to the improvements in surgical techniques and to the early diagnosis and management of complications after LT [2] .

As a consequence of these achievements, indications for LT have been expanded resulting in a growing demand for transplantable grafts and in a dramatic organ shortage. Therefore, one of the main ongoing challenges the transplant community is facing is to expand the donor pool in order to minimize the rate of patient death on the waiting list [3].

On the other hand, liver transplanted patients are surviving longer after the operation and longterm outcomes are becoming the main concern for clinicians, who have to deal with direct and indirect side effects of immunosuppressive therapy. The first human orthotopic liver transplantation (LT) in Europe was performed by Sir Roy Calne in Cambridge in 1968 [4], only one year after the first successful human liver transplantation reported by Thomas Starzl in the United States [5]. 
According to the United Network for Organ Sharing/Organ Procurement and Transplantation Network registry, hepatocellular carcinoma and hepatitis $\mathrm{C}$ virus cirrhosis are the most common diseases leading to liver transplantation, although increasing numbers of patients with alcoholic cirrhosis and nonalcoholic steatohepatitis are receiving transplants [6].

\section{Patients and Methods}

This study was conducted on 24 Egyptian patients with end stage liver disease caused by HCV genotype 4 and their donors that had underwent living donor liver transplantation at liver transplantation Unit at El Manial, Cairo University Hospital October 2012 to October 2015.

These patients received regular follow-up evaluations for two years post liver transplantation, which include clinical and serum biochemical assessments. The study was approved by the Institutional Ethics Committee of Cairo University. Written informed consent was obtained from each patient before the enrollment.

\section{Study population:}

Patients undergoing living donor liver transplantation (LDLT) for end stage liver disease due to $\mathrm{HCV}$ infection and Normal adult donors at liver transplantation Unit at El Manial, Cairo University Hospital.

\section{Inclusion criteria:}

Patients undergoing living donor liver transplantation (LDLT) for end stage liver disease due to $\mathrm{HCV}$ infection and Normal adult donors.

\section{Exclusion criteria:}

Patients undergoing living donor liver transplantation (LDLT) for end stage liver disease due to any etiology other than HCV infection or patients with co-infection with HBV or HIV.

\section{Our patients received treatment in the form of:}

Treatment with Peg Interferon a 2a 180ug per week and Ribavirin (400-1200 mg by mouth daily) for 48 weeks was initiated in patients with biopsyproven $\mathrm{HCV}$ recurrence. During the time of our study, Direct Acting Antivirals (DAA) were introduced in Egypt. So 14 patients in our study received DAA agents to treat $\mathrm{HCV}$ recurrence, 4 of these patients were INF/RVB experienced.

Follow-up and monitoring response to antiviral therapy:

Quantitative HCV RNA by polymerase chain reaction (PCR) was performed after 12 weeks of therapy to determine Early Virological Response (EVR) (>2-log drop or loss of HCV RNA) upon which the decision to continue treatment after 12 weeks is obtained then after 24 weeks, 48 weeks to determine End of treatment response (ETR) and finally 24 weeks after stoppage of treatment to find out those who develop Sustained virological response (SVR) or those who relapse (Relapsers). For those who received DAA agents, SVR was considered if HCV PCR done 12 weeks after end of treatment proved to be negative.

\section{DNA extraction \& IL28 B genotyping:}

Peripheral blood on EDTA was withdrawn from all subjects and genomic DNA was extracted from the whole blood sample using genomic DNA extraction kits QIAamp ${ }^{\circledR}$ DNA Blood Mini Kit. DNA samples were subjected to DNA quantitation and purity assessment using the NanoDrop ${ }^{\circledR}(\mathrm{ND})$ 1000 spectrophotometer (NanoDrop Technologies, Inc. Wilmington, USA). Recipient DNA and donor DNA were genotyped for the DNA polymorphism rs12979860 near the IL-28B gene with a custom TaqMan ${ }^{\circledR}$ single-nucleotide polymorphism SNP Genotyping Assays (Applied Biosystems) in Qiaplex thermal cycler.

\section{Statistical analysis:}

Data will be coded and entered using the statistical package SPSS version 17.0 Data will be summarized using mean, standard deviation and range (minimum and maximum) for quantitative variables and number and percent for qualitative variables. Comparisons between groups will be done using Chi-square test and fisher's exact test for qualitative variables while, independent sample. $t$-test for normally distributed quantitative variables and non parametric Mann Whitney test will be used for quantitative variables which are not normally distributed. $p$-values less than or equal to 0.05 were considered as statistically significant. Logistic regression to control the effect of other variables that are associated with treatment response will be done.

\section{Results}

All 24 subjects underwent liver transplantation as they suffered from end stage liver disease due to HCV infection. They all underwent liver transplantation between the years 2007 and 2014. The 24 recipients were 22 males and 2 females, while the 24 donors were categorized into 19 males and 5 females. (Table 1).

Mean age of recipients was 50 years at the date of transplantation (Table 1). All the patients had 
Child Pugh score "C". The mean MELD score was 18.45 (Table 1). Biliary complications due to anastomotic strictures occurred in 12 patients $(50 \%)$ and resolved by ERCP \& stenting. Acute graft rejection occurred in 2 patients $(8.33 \%)$, and they received pulse steroids. Late cellular rejection occurred in 2 patients $(8.33 \%)$ and treated by increasing baseline immunosuppressive drugs.

Table (1): Baseline characteristics of studied population.

\begin{tabular}{ll}
\hline Patient characteristics & \\
\hline Gender & $\begin{array}{l}\text { Recipient: M 22 F 2 } \\
\text { Donor: M 19 F 5 }\end{array}$ \\
Age (Mean \& SD.) & $50( \pm 5.9)$ \\
Hepatic focal lesions & $4 / 24$ \\
HCC confirmed & $3 / 24(12.5 \%)$ \\
MELD (Mean \& SD.) & $18.45( \pm 3.27)$ \\
Biliary complications & $12 / 24(50 \%)$ \\
Acute rejection & $2 / 24(8.3 \%)$ \\
Number of cases received & 10 \\
PEG IFN and SVR & SVR: $5 / 10$ \\
Number of cases received & 14 \\
DAA and SVR & SVR: $14 / 14$ \\
Number of cases who did liver & $19 \mathrm{FO}-\mathrm{F} 1=11 / 19(58 \%)$ \\
biopsy \& Fibrosis score & $\geq \mathrm{F} 2=8 / 19(42 \%)$ \\
\hline
\end{tabular}

To assess the effect of IL-28B Single nucleotide polymorphism (SNP) on HCV treatment response after transplant, an analysis of SVR rates in relation to IL-28B genotypes from donors and recipients was performed. The rate of SVR according to recipient and donor IL-28B genotype pairs was shown in Table (2).

Only 10 subjects in our study received Interferon/Ribavirin antiviral treatment. Among which $5 / 10$ patients achieved sustained virological response (SVR). The other $5 / 10$ patients were non responders to Interferon/Ribavirin antiviral treatment. (Table 2).

Table (2): SVR rates post IFN based therapy in relation to IL 28 B genotypes from Donors and recipients.

\begin{tabular}{lcccc}
\hline & SVR & Non-responders & \multicolumn{2}{c}{ Total } \\
\hline Recipients & & & & \\
IL 28B: & & 0 & 0 & 10 \\
$\quad$ CC & 0 & 5 & 10 & \\
$\quad$ Non-CC & 5 & & & \\
Donors & & & & \\
IL 28B: & 5 & 0 & 5 & 10 \\
$\quad$ CC & 5 & 5 & 5 & \\
$\quad$ Non-CC & 0 & & & \\
\hline
\end{tabular}

The recipient IL $28 \mathrm{~b}$ genotype of all 10 patients who received INF/RBV was non-CC, of whom $5 / 10$ cases were non responders or relapsers to treatment, while 5/10 achieved sustained virological response (SVR). Therefore no association was shown between SVR and recipient IL28B genotype in our study. (Table 2).

The 10 donors genotypes for patients received INF/RBV was non-CC in 5/10 cases where the patient did not achieve SVR, and CC in 5/10 cases where the patient achieved SVR. There is a statistical trend of association between donor IL28B rs 12979860 CC genotype with SVR in our study despite the small number of patients in our study that did not allow us to reach a statistical significance. (Table 2).

To understand if there is an additive effect of both recipient and donor IL28B genotypes, SVR was assessed based on each possible recipient and donor genotype combination. When recipients and donors were grouped together in pairs, the rate of SVR was found in group of non-CC recipients with $\mathrm{CC}$ donors. While it was not achieved in the group of non-CC recipients and non-CC donors. Despite not reaching statistical significance due to small number of cases, this result strongly suggests that the favorable IL 28B genotype is associated with SVR. (Table 3).

Table (3): Treatment response according to IL-28B genotype in recipient/donor pairs.

\begin{tabular}{lccc}
\hline IL 28B & SVR to \\
Recipient/Donor & INF/RB V & $\begin{array}{c}\text { Non-responders to } \\
\text { INF/RB V }\end{array}$ & Total \\
\hline Non-CC/Non CC & - & 5 & 5 \\
Non-CC/CC & 5 & - & 5 \\
\hline
\end{tabular}

In our study, 14 out of 24 patients received DAAs, they all achieved SVR. Four patients were Interferon experienced subjects and 10 were naive patients.

Out of the 14 patients who received DAA agents in our study, 8/14 cases achieved SVR, IL 28B of recipients was 7 non-CC and one $\mathrm{CC}$ (Table 4), and in donors $4 / 8$ non-CC and 4/8 CC. (Table 5).

While 6/14 relapsed, where 5 cases had received Dual therapy (Sof/Riba) and one case received Triple IFN based therapy, they all achieved SVR after receiving (Sofosbuvir/Daclatasvir). All of these 6 relapsers had IL 28 B genotype non-CC, and in donors 5/6 non-CC and 1/6 CC. (Tables 4,5). 
Table (4): Recipient IL 28B \& response to treatment by DAA agents.

\begin{tabular}{lcccc}
\hline Recipients IL 28B & SVR & Relapsers & \multicolumn{2}{c}{ Total } \\
\hline CC & 1 & 0 & 1 & 14 \\
Non-CC & 7 & 6 & 13 & \\
\hline Total & 8 & 6 & 14 \\
\hline
\end{tabular}

Table (5): Donor IL 28B \& response to treatment by DAA agents.

\begin{tabular}{lcccc}
\hline Donor IL 28B & SVR & Relapsers & \multicolumn{2}{c}{ Total } \\
\hline CC & 4 & 1 & 5 & 14 \\
Non-CC & 4 & 5 & 9 & \\
\hline Total & 8 & 6 & \multicolumn{2}{l}{14} \\
\hline
\end{tabular}

Table (6): Impact of DAA on IL 28B genotypes in Recipient/donor pairs.

\begin{tabular}{lccc}
\hline Recipient/donor & SVR & Relapsers & Total \\
\hline Non-CC-Non CC & 4 & 5 & 9 \\
Non-CC-CC & 3 & 1 & 4 \\
CC-CC & 1 & 0 & 1 \\
\hline Total & 8 & 6 & 14 \\
\hline
\end{tabular}

Regarding the impact of recipient-donor pairs on SVR post DAAs treatment, it was found that among 8 patients who achieved SVR, $4 / 8$ cases (50\%) were non-CC/non CC and the other 4 had at least one favorable genotype, among the 6 relapsers $5 / 6$ cases were non-CC/non CC (83.3\%) and one case non-CC/CC. (Table 6).

No statistically significant difference in response to DAAs was identified according to recipient or donor IL-28B polymorphism.

All different recipient/donor patterns of IL-28B showed SVR eventually in response to treatment by Direct Acting Antiviral agents combinations. Despite not reaching statistical significance due to small number of cases, it was obvious that the non-CC genotype was dominant in relapsers either in recipients or donors, and patients with a favorable IL 28B genotype can be successfully treated with shorter, simpler or cheaper regimens.

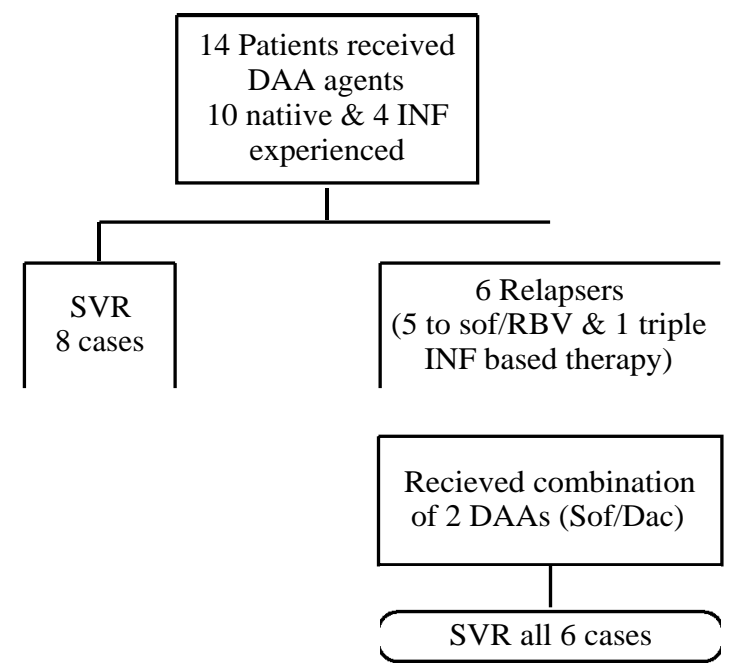

Fig. (1): Diagram showing response of treated patients to DAA.

\section{Discussion}

Genetic variation in the IL28B gene, which encodes the antiviral cytokine IFN-gamma, is strongly associated with SVR in patients with chronic HCV infection treated with PEG-IFN/ RBV. A genome-wide association study of more than 1,600 patients infected with HCV genotype 1 found that the rate of SVR following PEG-IFN/ RBV treatment to be approximately $80 \%, 40 \%$, and $25 \%$ in IL28B genotypes CC, CT, and TT, respectively [7]. Recent studies have reported that spontaneous clearance of acute hepatitis $\mathrm{C}$ and sustained viral response after antiviral treatment (AVT) of chronic hepatitis C, caused by HCV in non-transplanted patients, is much higher in patients with IL-28B CC than non-CC genotype [8]. Also in patients with $\mathrm{HCV}$ recurrence after liver transplantation the IL-28 genotype seem to have a strong influence both on the natural course of HCV recurrence and on treatment response [9]. While viral clearance is unlikely to occur after LT, Allam et al., [10] hypothesized that IL28B genotype was associated with an altered innate immune response (e.g. interferon-stimulated genes) to induce an antiviral state [10]. This is in agreement with data that the expression of hepatic interferon-stimulated genes was strongly associated with IL28B variants producing a more favorable immunologic profile for viral clearance [11].

In the present study, the donor rs 12979860 genotype was strongly associated with the success of PEG-IFN-a and ribavirin treatment of recurrent hepatitis $\mathrm{C}, 10$ patients were treated with PEGIFN-a and ribavirin, where 5 cases with a donor CC genotype achieved SVR and the other with a non-CC genotype did not. A trend was noted here 
that donors with a favorable IL 28B genotype achieved SVR although the small number of patients in our study did not allow us to reach a statistical significance, we observed a strong association of the donor IL 28B genotype and SVR to PEG-IFN-a and ribavirin treatment of recurrent hepatitis $\mathrm{C}$, an association between SVR and the recipient's IL 28B was not noticed as all 10 patients treated with PEG-IFN- a and ribavirin had non$\mathrm{CC}$ genotype.

Our findings are consistent with findings of Meuller et al., [12] that confirmed the favorable association of the IL28B 12979860 CC genotype with response to Anti Viral Treatment (AVT) and SVR [12]. There had been increasing evidence that the IL-28B polymorphism was a strong predictor of a sustained virological response in patients treated for recurrent $\mathrm{HCV}$ after liver transplantation [13]. Patients with CC genotype either at baseline or in the donor liver had significantly higher response rates to IFN therapy than the non-CC genotypes, while the donor liver CC genotype was more predictive for better outcome than the recipient's [14].

Lange et al., [15] in his study had patients that achieved SVR despite an unfavorable donor rs 12979860 genotype. These patients had a favorable recipient rs 12979860 genotype. Thus, the donor IL28B genotype appeared to be a stronger but not exclusive predictor of treatment outcome of HCV liver graft reinfection; and recipient IL28B genotypes and/or other host and/or viral factors may have salvaging properties in case of an unfavorable donor IL28B genetic background [15]

Similar to the results of Charlton et al., [16], our data showed that patients with CC genotype had generally better response to IFN therapy, especially if the donor liver was also CC genotype. Charlton study combined the group of $\mathrm{CC} / \mathrm{r}$ : non$\mathrm{CC} / \mathrm{d}$ with CC/d: non-CC/r for a $50 \% \mathrm{SVR}$. We had a higher SVR rate in those who were CC/d: non-CC/r. On the contrary, patients with non-CC genotype who also received a donor liver with non-CC genotype had much lower chance of response to therapy [16]. These findings suggest that patient's own IL-28B genotype is a predictor for SVR, implying that systemic immune responses may play a role in determining the response to therapy. In addition, patients with non-CC genotype who received a CC donor liver had better chance to achieve SVR than those patients who received a non-CC donor liver. This finding suggests that liver innate antiviral response may play a more important role in the outcome of the treatment [17]
Similarly, as in the non-transplanted patients, the IL-28B CC genotype in transplant recipients is associated with higher SVR rates after AVT treatment than the non-CC genotype [15]. Hence, non-CC recipients are more likely to be prior nonresponders to treatment with AVT increasing the proportion of non-CC patients among liver transplant recipients. In our study we could not prove that recipient gene polymorphism had an impact on SVR as we didn't have any CC recipient patient included in cases treated with PEG-IFN- a and ribavirin.

A trend, however, was seen also in the study of Ackefors et al., [18], towards a more favorable treatment outcome in recipients with grafts from donors with the IL-28B CC genotype. In matched donor/recipient $(\mathrm{D} / \mathrm{R})$ pairs, the most favorable $\mathrm{D} / \mathrm{R}$ combination CC/CC in his study yielded an SVR rate of $50 \%$ VS 36\% in the most unfavorable $\mathrm{D} / \mathrm{R}$ combination non-CC/non-CC. Due to the small numbers, however, this difference did not reach statistical significance, for this, larger studies are needed [18]

Coto-Llerena [19], tested the effects of the IL28B genotypes in 128 European donor and recipient pairs and found that the recipient genotype played a major role in the response to therapy, while donors effect depended on a favorable recipient IL28B genotype [19]. Lange et al., [15], also showed in his study equal effects of donor and recipient IL-28B genotypes on the virological response [15] Concerning the importance of donor IL-28B genotype, Ackefors et al., [18], did not see any significant correlation between donor IL-28B genotype and SVR after AVT treatment [18]. On the other hand Allam et al., [10]. Found a trend towards lower rates of SVR in the IL28B TT, but neither recipient nor donor IL28B status were significantly associated with SVR after anti-HCV treatment as it was observed in other studies. All these studies did not find an association between the donor gene polymorphism and SVR unlike our study. They found equal impact between recipient and donor, this might be due to the presence of cases with the favorable gene $\mathrm{CC}$ among recipients in their study unlike our study where all recipients who received AVT had the unfavorable non-CC genotype. All these studies demonstrated that Il-28b gene polymorphism had an impact on SVR. The lack of an association and lower rate of SVR in these studies might be due to ethnic differences, timing of treatment initiation, disease severity, treatment adherence, the type (deceased versus living) and quality of the donor organ (e.g. donor age). Also it remains unknown whether and to what extent the transplant- 
ed liver may be repopulated by host cells which may alter the relevance of the donor vs. recipient genotypes in a time-dependent manner [15]. Our observations may point to functional implications of IL28B genetic polymorphisms. Indeed, the important role of the donor rs 12979860 genotype suggests that IL28B genetic polymorphisms may act in the liver (i.e., donor-derived) cells. However, whether these genetic variants primarily affect molecular pathways within hepatocytes or other intra-hepatic cells, such as Kupffer cells, remains to be explored. An additional role for IL28B genetic polymorphisms in extra-hepatic (i.e., recipientderived) tissues or liver-infiltrating innate or adaptive immune cells is supported by associations of recipient IL28B genetic variants with virological response rates [15]

A number of studies have now firmly established the association of IL-28B SNP and HCV infection outcome and treatment response. However, the underlying mechanisms of action remain elusive. The $\mathrm{C}$ or $\mathrm{T}$ allele of the IL-28B does not appear to affect the protein expression levels of the cytokine [19]. It is more likely that this SNP somehow changes the immune response, the virus and the interferon signaling pathways. These changes will definitely affect the systemic immunity and the innate antiviral system of the HCV natural host, the liver [17].

The IL28B genotype status is the most important pretreatment predictor to PEG-IFN a/RBV therapy [20]. The approval of the first generation of NS3 protease inhibitors represented a significant advance for the field [21]. IL28B genotype will remain relevant to the outcomes of DAA therapy when used in combination with a PEG INF/RBV backbone [22].

In our study 14 cases received DAA agents, 8/14 achieved SVR after their $1^{\text {st }}$ treatment option which was dual therapy, triple therapy, Sofosbuvir/ ledipasvir or Sofosbuvir/Daclatasvir, while 6/14 failed their first line of treatment which was triple therapy in one case and dual therapy in 5 cases, out of these 5 cases who had failed dual therapy, 3 cases had failed PEG INF/RBV previously and they had nonCC/nonCC genotypes combination. These 6 patients then achieved SVR after receiving 2 DAAs plus Ribavirin (Sof/Dacla/RBV). In the 8 cases who achieved SVR after 1 st line treatment the IL $28 \mathrm{~B}$ of recipients was non-CC in $7 / 8$ cases and $\mathrm{CC}$ in $1 / 8$, and donors $4 / 8$ non-CC and $4 / 8$ CC. In regard of recipient/donor genotypes pairs, there were 4 cases of non-CC/non-CC, 3 cases non- $\mathrm{CC} / \mathrm{CC}$ and 1 case CC/CC. In the 6 cases who achieved SVR after 2 nd line of treatment by DAA agents the IL $28 \mathrm{~B}$ genotype of recipients was non$\mathrm{CC}$ in all cases, and in donors non-CC in $5 / 6$ cases and $\mathrm{CC}$ in $1 / 6$ case. In pairs, they were 5 cases of non-CC/non-CC, and one case non-CC/CC.

Overall in the 14 patients who received DAA agents and achieved SVR the IL 28B of recipients was predominantly non-CC $13 / 14$ and $1 / 14$ CC, owing to previously demonstrated findings of the lower prevalence of $\mathrm{CC}$ genotype in $\mathrm{HCV}$ infected liver transplantation (LT) recipients. In donors $9 / 14$ were non-CC, and 5/9 CC giving no significant difference in the relation of IL $28 \mathrm{~B}$ polymorphism in donors and SVR after DAA agents treatment of $\mathrm{HCV}$. In recipient/donor pairs, there were $9 / 14$ cases non-CC/non-CC, 4/14 non-CC/CC and 1/14 $\mathrm{CC} / \mathrm{CC}$. No statistically significant difference was also seen as regard the recipient/donor pattern and SVR to DAA agents.

In accordance with our findings Pol et al., [23] showed that the IL28B genotypes (SNP rs12979860) did not show differences in SVR rates across the genotypes and according to prior response [23]. Also Bacon et al., [24] in his study of patients who had failed prior therapy with PEGIFNa/RBV (relapsers and partial responders) showed that IL28B polymorphisms did not have a significant effect on SVR [24]

Lok et al., in a small study of prior null responders that were treated using the combination of daclatasvir (NS5I) plus asunaprevir (PI), 9/10 patients carried a poor response IL28B genotype. 10/10 patients achieved an SVR [25]. On the contrary Poordad et al., [26]. Presented data pointing to IL28B status as the most important pretreatment predictor of response in patients receiving triple therapy [26]. Also Zeuzem et al., [27] showed that the IL28B CC genotype was significantly predictive of a favorable response to therapy as defined by SVR in all arms. In addition, IL28B CC genotype can also be used as a predictor of eligibility for shortened therapy as it was significantly associated with undetectable HCV RNA after 8 weeks of therapy [27]. Although Holmes et al., [21]. Noted that the association between IL28B polymorphism and treatment outcome is attenuated in the setting of triple therapy, he also noted that the IL28B genotype is also associated with the response to IFN-free regimens, and $\mathrm{C} / \mathrm{C}$ patients remain easier to cure [21]. Kowdley et al., [28] showed that the good response IL28B genotype had predicted shortduration therapy using response-guided regimens [28]. Jacobson et al., [29]. Demonstrated an increased SVR across all IL28B genotypes, but patients with the favorable CC genotype still had 
the best outcome as determined by SVR. In addition, patients with the CC genotype were most likely to have shortened durations of therapy [29] The differences between these findings and our findings may be owed to the small number of cases in our study. Also most of these studies did demonstrate the same finding in our study about most of the cases eventually achieving SVR, except that they demonstrated higher rates of on-treatment response as well as SVR in patients with favorable IL-28B genotype identifying the likelihood of an individual being eligible for short-duration therapy. In our study the lack of data about the possibility of early viral clearance of patients on-treatment rendered us unable to show that finding.

As more potent DAA combinations are developed, that do not require an IFN backbone, it will be important to note how valuable these pretreatment predictors will be. There is also increasing evidence that potent DAA regimens reduce the importance of IL28B genotype status as a determinant of the likelihood of response. It seems likely that it will be possible to overcome the effect of IL28B polymorphism with the combination of 2 DAAs.

Combinations of best-in-class DAAs are likely to achieve very high SVR rates, and IL28B polymorphism will no longer predict treatment outcome. However, IL28B genotyping may remain useful if it can be used to individualize treatment strategies, identifying patients who can be successfully treated with shorter, simpler or cheaper regimens [21]

\section{Summary \& Conclusion:}

Our study revealed that the donor rs 12979860 $\mathrm{CC}$ genotype was strongly associated with the success of PEG-IFN-a and ribavirin treatment of recurrent hepatitis $\mathrm{C}$.

No impact of IL 28B polymorphism on the response to anti viral treatment (AVT) by direct acting antiviral (DAA) agents, as all different IL 28B genotypes and different recipient/donor patterns eventually achieved SVR even in cases with two unfavorable non-CC genotypes in both recipients and donors.

\section{References}

1- ADAM R., McMASTER P., O'GRADY J.G., CASTAING D., KLEMPNAUER J.L., et al.: Evolution of liver transplantation in Europe: Report of the European Liver Transplant Registry. Liver Transpl., 9: 1231-1243, 2012.

2- MIHAI-CALIN P. and JOSEP F.: Expansion of the hepatocellular carcinoma Milan criteria in liver transplantation: Future directions. World J. Gastroenterol., 24 (32): 3626$3636,2018$.
3- MONTENOVO M.I., DICK A.A. and HANSEN R.N.: Donor hepatitis $\mathrm{C}$ sero-status does not impact survival in liver transplantation. Ann Transplant. Jan., 22 (20): 44 $50,2015$.

4- CALNE R.Y., WILLIAMS R., DAWSON J.L., ANSELL I.D., et al.: Liver transplantation in man. II. A report of two orthotopic liver transplants in adult recipients. $\mathrm{Br}$. Med. J. Nov 30; 4 (5630): 541-6, 1968.

5- STARZL T.E., BRETTSCHNEIDER L. and GROTH C.G.: Liver transplantation. Bull Soc. Int. Chir. Sep., 26 (5): 474-88, 1967.

6- YANG J.D., LARSON J.J., WATT K.D., et al.: Hepatocellular Carcinoma Is the Most Common Indication for Liver Transplantation and Placement on the Waitlist in the United States. Clin. Gastroenterol. Hepatol., 15: 767, 2017.

7- HISHAM E. ZIDAN, RANDA M. TALAAT, AMAL A.A AMMAR and MOUSTAFA A. SAKR: Interleukin 28B Polymorphism as a Predictor of Response to Treatment of Egyptian HCV Patients Working in Nuclear Material Authority. The Egyptian Journal of Hospital Medicine, 77 (1), 4742-4747, 2019.

8- NATALIA E., DANIELA C., PABLO L., ADRIANA S. CICERON, JENNIFFER A., et al.: IL28B gene polymorphism rs12979860, but not rs8099917, contributes to the occurrence of chronic HCV infection in Uruguayan patients. Virology Journal, 15: 40, 2018.

9- ABID S., MOSIN S. KHAN, SYED M., ZAFFAR K., ALTAF H SHAH, et al.: The role of biochemical variations and genotype testing in determining the virological response of patients infected with hepatitis $C$ virus. Journal of Global Infectious Diseases, 10 (2): 89-98, 2018.

10- S. ALLAM, B. KRUGER, A. MEHROTRA, T. SCHIANO, B. SCHROPPEL, et al.: The Association of IL28B Polymorphism and Graft Survival in Patients with Hepatitis C Undergoing Liver Transplantation PLOS ONE January, Volume 8, Issue 1, e54854, 2013.

11- BAKR A., GHONEIM E., SAYED M., EL-MOTTALEB T.A., SABAWY M.E., et al.: Interleukin 28B polymorphism as a predictor of response to interferon therapy in hepatitis C virus patients. Menoufia Med. J., 28: 670-6, 2015.

12- J. MUELLER, L. KING, K. JOHNSON, T. GAO, et al.: Impact of EGF, IL28B, and PNPLA3 polymorphisms on the outcome of allograft hepatitis C: A multicenter study. Clin. Transplant. Apr., 30 (4): 452-460, 2016.

13- GRAZIADEI I.W., ZOLLER H.M., NOBLE B., et al.: Early viral load and recipient IL28B rs12979860 genotype are predictors for progression of hepatitis $\mathrm{C}$ after liver transplantation. Liver Transpl., 18 (6): 671-679, 2012.

14- FIRPI R.J., DONG H., CLARK V.C., SOLDEVILA-PICO C., MORELLI G., CABRERA R., et al.: CC genotype donors for the interleukin-28B single nucleotide polymorphism are associated with better outcomes in hepatitis C after liver transplant. Liver Int., 33:72-78. doi: 10.1111/liv.12013, 2013.

15- LANGE C.M., MORADPOUR D., DOEHRING A., et al.: Impact of donor and recipient IL28B rs12979860 genotypes on hepatitis $\mathrm{C}$ virus liver graft reinfection. J. Hepatol., 55 (2): 322-327, 2011. 
16- CHARLTON M.R., THOMPSON A., VELDT B.J., et al.: Interleukin-28B polymorphisms are associated with histological recurrence and treatment response following liver transplantation in patients with hepatitis $\mathrm{C}$ virus infection. Hepatology, 53 (1): 317-324, 2011.

17- TAJANA FILIPEC KANIZAJ and NINO KUNAC: Hepatitis C: New challenges in liver transplantation. World J Gastroenterol. May, 21; 21 (19): 5768-5777, 2015.

18- M. ACKEFORS, J. NYSTRaOM, A. WERNERSON, H. GJERTSEN, A. SaONNERBORG and O. WEILAND: Evolution of fibrosis during HCV recurrence after liver transplantation-influence of IL-28B SNP and response to peg-IFN and ribavirin treatment. Journal of Viral Hepatitis, 20: 770-778, 2013.

19- CYR D.D., LUCAS J.E., THOMPSON J.W., et al.: Characterization of serum proteins associated with IL28B genotype among patients with chronic hepatitis C. PLoS ONE, 6: e21854, 2011.

20- ZHONGJIE HU, YING LIU, LIXIA QIU, ZUOPENG FAN, WEI NIE, et al.: Kinetic response of wild and mutant core codon 70 strains of HCV genotype $1 \mathrm{~b}$ to pegylated interferon- $a$ and ribavirin therapy. Virology Journal, 12, Article number: 220, 2015.

21- J.A. HOLMES, P.V. DESMOND and A.J. THOMPSON: Does IL28B genotyping still have a role in the era of direct-acting antiviral therapy for chronic hepatitis $\mathrm{C}$ infection? Journal of viral hepatitis Volume 19, Issue 10 October, 677-684, 2012.

22- GAMAL ELDEEN E., WAFA A., RASHA A., AHMED A. TAHA, DINA S., et al.: Hepatitis C Viral Kinetic Changes in a Retrospective Cohort Study of Chronic Hepatitis C Virus Egyptian Patients on Pegylated Interferon and Ribavirin Therapy. Journal of Interferon \& Cytokine Research, 36 (3), 2016.

23- POL S., AERSSENS J., ZEUZEM S., et al.: Similar SVR rates in IL28B CC, CT or TT prior relapser, partial- or null-responder patients treated with telaprevir / peginterferon/ribavirin: Retrospective analysis of the REALIZE study. Journal of Hepatology, 54. S6 (A13), 2011.

24- BACON B.R., GORDON S.C., LAWITZ E., et al.: Boceprevir for previously treated chronic HCV genotype 1 infection. N. Engl. J. Med., 364: 1207-17, 2011.

25- LOK A.S., GARDINER D.F., LAWITZ E., et al.: Combination therapy with BMS-790052 and BMS-650032 alone or with pegIFN/RBV results in undetectable HCV RNA through 12 weeks of therapy in HCV genotype 1 null responders. J. Hepatol., 54. (LB-8), 2011.

26- POORDAD F., BRONOWICKI J.P., GORDON S.C., ZEUZEM S., JACOBSON I.M., et al.: Factors that predict response of patients with hepatitis $\mathrm{C}$ virus infection to boceprevir. Gastroenterology. Sep., 143 (3): 608-618.e5, 2012.

27- ZEUZEM S., ANDREONE P., POL S., et al.: Telaprevir for retreatment of HCV infection. N. Engl. J. Med., 364: 2417-28, 2011.

28- KOWDLEY K.V., LAWITZ E., CRESPO I., et al.: ATOMIC: 97\% RVR for PSI-7977+ PEG/RBV x 12 week regimen in HCV GT1: An end to response-guided therapy? J. Hepatol., 56: S1-A1, 2012.

29- JACOBSON I.M., McHUTCHISON J.G., DUSHEIKO G., et al.: Telaprevir for previously untreated chronic hepatitis C virus infection. N. Engl. J. Med., 364: 240516, 2011.

\section{تأثير تحور جين الانترلوكين بـ بـى على الاستجابة للعلاج من فيروس (سى)

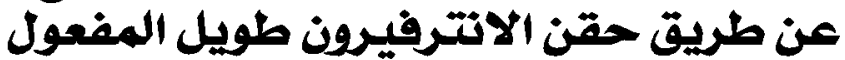

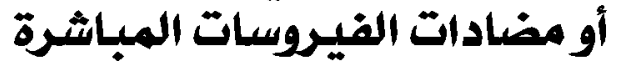

\footnotetext{
تهدف دراستتا للتحقيق فى تأثير تحود جين الانترلوكين ^ببى على الاستجابة للعلاج من فيرس (سى) عن طريق حقن الانترفيرن طويل المفعل أو مضادات الفيروبسات المباشرة.

وقد أخذ مريض علاج على هيئة حقن الانترفيرون طويل المفعول مع الريبافيرين، بينما أخذ عشرة مرضى مضادات، (الفيروبسات المباشرة للعلاج من فيروس سىى).

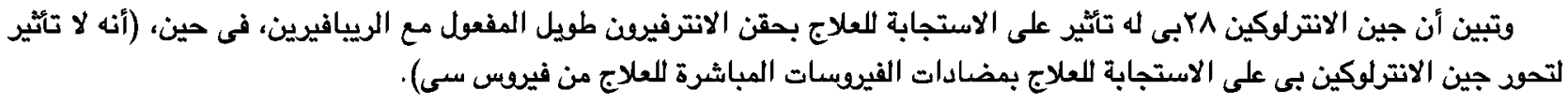

وقد أظهرت النتائج أن نسب الشفاء المرتفعة المصاحبة للعلاج من فيروس (سى) عن طريق مضادات الفيرسات المباشرة (تقلل من أهمية

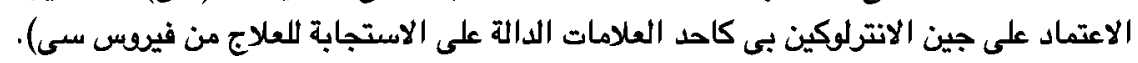

